\title{
Esterifications with 2-(Trimethylsilyl)ethyl 2,2,2- trichloroacetimidate
}

\author{
Wenhong Lin, Shea T. Meyer, Shawn Dormann and John D. Chisholm* \\ Department of Chemistry, Syracuse University, 1-014 Center for Science and Technology, \\ Syracuse, NY 13244
}

jdchisho@syr.edu

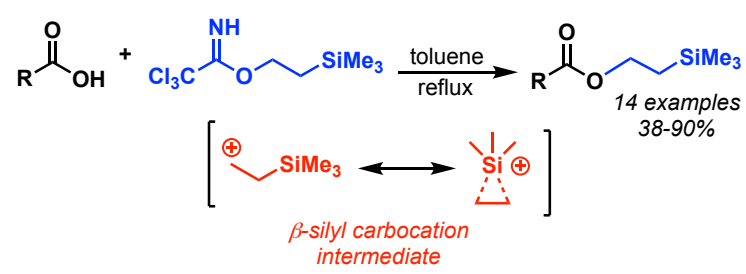

\begin{abstract}
2-(Trimethylsilyl)ethyl 2,2,2-trichloroacetimidate is readily synthesized from 2trimethylsilylethanol in high yield. This imidate is an effective reagent for the formation of 2trimethylsilylethyl esters without the need for an exogenous promoter or catalyst, as the carboxylic acid substrate is acidic enough to promote ester formation without an additive. Deuterium labeling studies indicate that a $\beta$-silyl carbocation intermediate is involved in the transformation.
\end{abstract}

Esters are ubiquitous protecting groups for organic molecules with carboxylic acid functionality. Demand for specialized esters that can be cleaved under mild conditions in complex molecules has led to the development of a number of creative solutions. ${ }^{1}$ The trimethylsilylethyl (TMSE) ester ${ }^{2}$ has become popular in this context, as the ester can be easily cleaved (with acid, ${ }^{3}$ 
base $^{4}$ or flouride ${ }^{5}$ ) without disturbing most other benzyl or alkyl esters. TMSE esters may also be transformed to other esters or lactones by capturing the carboxylate resulting from treatment with fluoride with an electrophile. ${ }^{6}$ Similar chemistry can be employed to decarboxylate TMSE protected $\beta$-keto esters, facilitating the enantioselective formation of all carbon quaternary centers. ${ }^{7}$ Despite its synthetic utility, the most common methods of forming TMSE esters directly from a carboxylic acid remain dependent on carbodiimide based reagents, ${ }^{2 a, 8}$ Mukaiyama's reagent, ${ }^{9}$ or utilize the Mitsunobu conditions. ${ }^{10}$ While effective these transformations are often plagued by issues with the separation of side products and also create significant waste streams.

Recently we have been involved in a number of studies evaluating the promoter free reactivity of trichloroacetimidate electrophiles with nitrogen, ${ }^{11}$ sulfur ${ }^{12}$ and oxygen ${ }^{13}$ nucleophiles. Carboxylic acids have been noted to be alkylated under promoter free conditions via symbiotic activation by trichloroacetimidates that are precursors to stabilized carbocations, including the 2phenylisopropyl, ${ }^{14}$ 4-methoxybenzyl, ${ }^{15}$ diphenylmethyl ${ }^{16}$ and tert-butyl imidates. ${ }^{17}$ Given that trichloroacetimidates are simple to prepare form inexpensive starting materials and that the esterifications often proceed under mild conditions without the need for an exogenous promoter or catalyst, the formation of TMSE esters using this chemistry was investigated. Use of the previously unknown trimethylsilylethyl trichloroacetimidate 2 , which may be a precursor to a $\beta$ silyl stabilized carbocation that can be trapped with an carboxylic acid, would provide a mild method for installing a TMSE ester with trichloroacetamide $\mathbf{4}$ as the sole by product, which is easily removed by washing with aqueous sodium hydroxide.

Initially the preparation of trimethylsilylethyl 2,2,2-trichloroactimidate $\mathbf{2}$ was investigated. Imidate 2 was readily formed in $97 \%$ yield by reaction of commercially available 2 trimethylsilanol with trichloroacetonitrile using DBU as a catalyst following the conditions 
developed by Schmidt and co-workers. ${ }^{18}$ With the imidate in hand the esterification reaction was explored (Table 1) using 3-nitrobenzoic acid $\mathbf{1}$ as a test substrate. Use of TMSOTf led to the destruction of the imidate without formation of any ester product. Switching to the Brønsted acids CSA and PPTS did provide some ester product when catalytic amounts of the acids were used, however the yields were low (entry 4 and 6). These poor yields were attributed to decomposition of the imidate in the presence of the strong acid catalysts. Esterification under promoter free conditions ${ }^{15-17}$ was then explored by heating carboxylic acid $\mathbf{1}$ and imidate $\mathbf{2}$ in refluxing toluene for 24 hours (entry 7). These conditions gave complete conversion to the TMSE ester, but the ester product was difficult to separate from the excess imidate. Allowing the reaction mixture to cool to rt and treating the mixture with $1 \% \mathrm{TFA} / \mathrm{H}_{2} \mathrm{O}$ was able to hydrolyze the excess imidate, and led to the isolation of an $81 \%$ yield of the desired ester 3 .

Table 1. Esterification of 3-Nitrobenzoic acid 1 with TMSE Imidate 2.

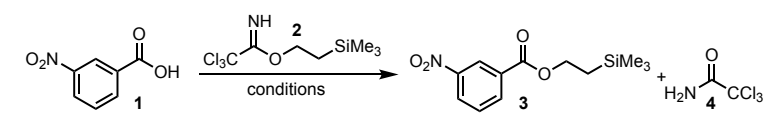

\begin{tabular}{|c|c|c|c|c|c|c|}
\hline entry & $\begin{array}{c}\text { equiv. } \\
\text { imidate }\end{array}$ & promoter & solvent & time & temp. & yield (\%) \\
\hline 1 & 1.2 & TMSOTf (1 equiv) & DCM & $1 \mathrm{~h}$ & $\mathrm{rt}$ & $0^{\mathrm{b}}$ \\
\hline 2 & 1.2 & TMSOTf (20 mol \%) & DCM & $1 \mathrm{~h}$ & $\mathrm{rt}$ & $0^{\mathrm{b}}$ \\
\hline 3 & 1.2 & CSA (1 equiv) & DCM & $1 \mathrm{~h}$ & $\mathrm{rt}$ & $0^{\mathrm{b}}$ \\
\hline 4 & 1.2 & CSA (20 mol \%) & DCM & $1 \mathrm{~h}$ & $\mathrm{rt}$ & 22 \\
\hline 5 & 1.2 & PPTS (1 equiv & DCM & $1 \mathrm{~h}$ & $\mathrm{rt}$ & $0^{\mathrm{b}}$ \\
\hline 6 & 1.2 & PPTS (20 mol \%) & DCM & $1 \mathrm{~h}$ & $\mathrm{rt}$ & 17 \\
\hline 7 & 2.0 & none & toluene & $24 \mathrm{~h}$ & reflux & $81^{\mathrm{c}}$ \\
\hline
\end{tabular}

${ }^{a}$ isolated yields.

${ }^{b}$ imidate was consumed, but SM acid remained.

${ }^{c}$ crude reaction was subjected to $1 \%$ aq. TFA to remove excess imidate.

The scope of the esterification reaction was then explored (Table 2). Benzoic acids bearing electron withdrawing groups generally gave higher yields than benzoic acids with electron donating groups. This is rationalized by the acid being both a substrate and a proton source which can activate the imidate. The lower yield observed with compound 7 was attributed to the 
sensitivity of this substrate, which has been shown to decompose when exposed to mild acid like silica gel or wet $\mathrm{CDCl}_{3 .}{ }^{19}$ Esters conjugated with alkenes (like 9) and alkynes (like 10) were also successfully formed under these reaction conditions. No isomerization of the $\mathrm{Z}$ alkene in ester 9 was observed in the crude ${ }^{1} \mathrm{H}$ NMR or the purified product. Alkyl substituted esters were also good substrates for the esterification reaction (Table 2, entries 6-12). The lower yield in the case of alkynyl ester $\mathbf{1 3}$ was due to difficulties in handling this volatile product. No racemization was observed in the formation of the naproxen ester 15, demonstrating that the conditions are compatible with nearby chiral centers. The presence of alcohols in the carboxylic acid was detrimental to the esterification process, however, as some of the alcohol was converted to the OTMS ether by the excess imidate. Clean conversion to the TMSE ester could be accomplished by using one equiv of imidate $\mathbf{2}$, however the yield of ester was lower when compared to other acids. In the case of ester $\mathbf{1 9}$ the yield was low, and the ester appeared to be undergoing decomposition. This may be due to side reactions between the indole and the imidate, as indoles are known to be alkylated with imidate electrophiles, ${ }^{20}$ although these reactions usually require a Lewis acid promoter. Lowering the reaction temperature to $100{ }^{\circ} \mathrm{C}$ and increasing the reaction time to $29 \mathrm{~h}$ improved the yield to $78 \%$ in this case. 
Table 2. Esterifications with 2-(Trimethylsilyl)ethyl 2,2,2-trichloroacetimidate

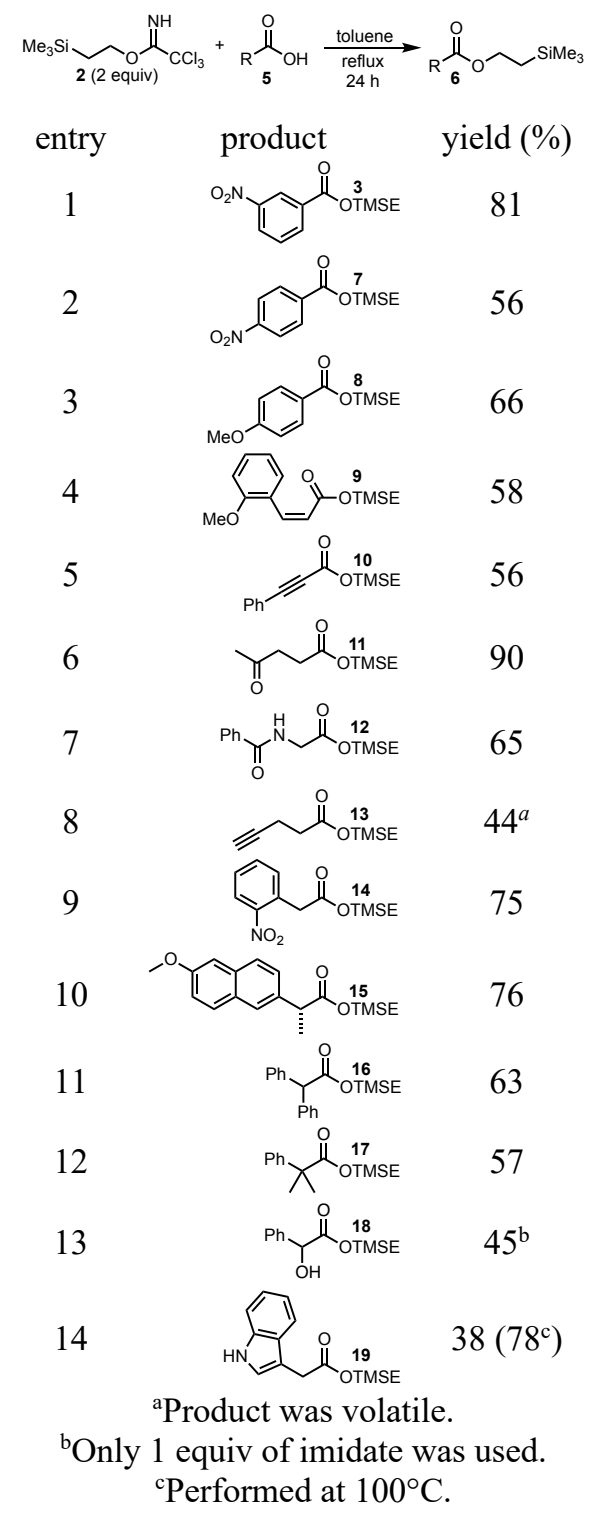

In earlier cases of thermal esterifications with trichloroacetimidates evidence suggested that carbocation intermediates were involved. ${ }^{17}$ For the esterification with 2-(trimethylsilyl)ethyl 2,2,2-trichloroacetimidate 2 this implicates the proposed mechanism shown in Figure 1. Proton transfer from the acid $\mathbf{5}$ to the imidate $\mathbf{2}$ forms the protonated imidate 20, which then dissociates trichloroacetamide 4 leading to the formation of the $\beta$-silyl carbocation 21. $\beta$-Silyl carbocations like $\mathbf{2 1}$ are known to be unusually stable due to hyperconjugation from the nearby silicon-carbon 
bond. ${ }^{21}$ Based on experimental and computational evidence, the structure of this cation is best represented by the bridged resonance structure $\mathbf{2 2}$ rather than the primary carbocation structure represented by $\mathbf{2 1} .^{21-22}$ Addition of the carboxylate to the cation $\mathbf{2 2}$ then provides the observed ester product.

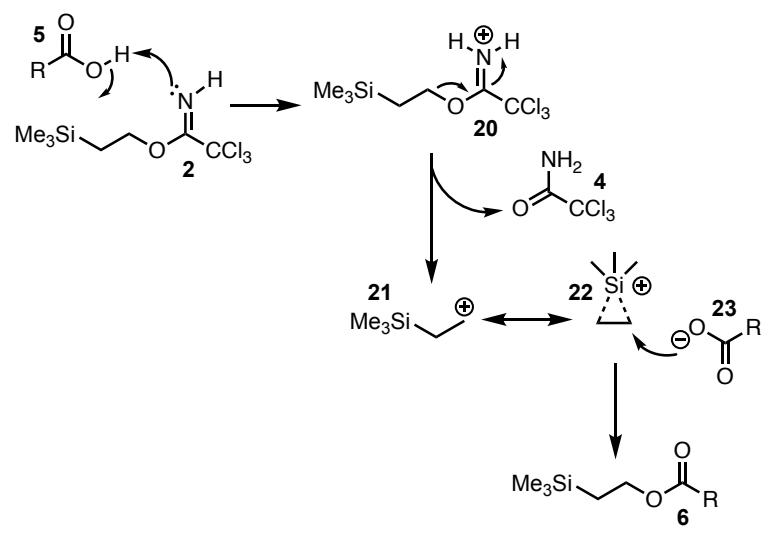

Figure 1. Proposed mechanism of the esterification.

While the ability of the trimethylsilyl group to stabilize a $\beta$-carbocation is well known, an $\mathrm{S}_{\mathrm{N}} 2$ mechanism where the carboxylate directly displaced the acetamide from the protonated imidate $\mathbf{2 0}$ could not be ruled out. To gain further insight into the reaction mechanism a deuterated version of imidate 2 was synthesized (Scheme 1). This involved the reduction of ethyl trimethylsilylacetate $\mathbf{2 4}$ with lithium triethylborodeuteride to provide the deuterated alcohol. This alcohol was then converted to the corresponding deuterated imidate $\mathbf{2}-d_{2}$, which was then subjected to esterification with 4-methoxybenzoic acid $\mathbf{2 5}$. This esterification resulted in the formation of two deuterated esters (26 and $\mathbf{2 7}$ ) in roughly equal amounts, implying that the $\beta$-silyl cation was indeed an intermediate in the esterification reaction. 


\section{Scheme 1}

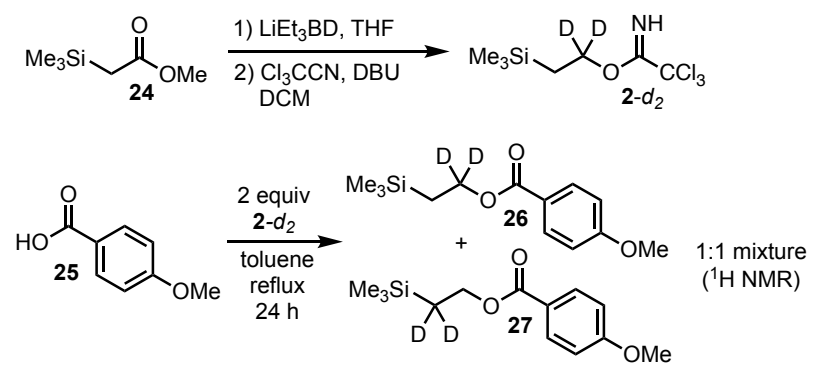

Attempts were also made to form trimethylsilylethyl ethers with alcohols and phenols under similar conditions (toluene, reflux). These experiments showed no formation of the TMSE ether, with the starting materials being recovered. Evidently phenols and alcohols are not acidic enough to promote etherification through activation of the imidate. Employing Lewis or Brønsted acids to catalyze or promote the formation of TMSE ethers (TMSOTf and CSA were used) led to decomposition of the imidate and only trace amounts of the desired TMSE ether, so these attempts were abandoned.

In summary, 2-(trimethylsilyl)ethyl 2,2,2-trichloroacetimidate has been prepared from the corresponding alcohol. This reagent provides a new method for the formation of the valuable TMSE esters by simply heating the unprotected carboxylic acid with the imidate. These thermal reactions proceed under near neutral conditions and create significantly less waste than other transformations which depend on carbodiimide and diazodicarboxylate based reagents. Mechanistic studies imply that the esterifications proceed through a carbocation manifold.

\section{Supporting Information}

Copies of ${ }^{1} \mathrm{H}$ NMR and ${ }^{13} \mathrm{C}$ NMR spectra of new compounds and full experimental details. This material is available free of charge via the Internet.

\section{Author Information}




\section{Corresponding Author}

*E-mail: jdchisho@syr.edu

\section{Notes}

The authors declare no competing financial interest.

\section{Acknowledgements}

Christopher M. Russo is thanked for some preliminary experiments.

\section{References}

(1) (a) Wuts, P. G. M. Greene's Protective Groups in Organic Synthesis; 5th ed.; John Wiley \& Sons: Hoboken, NJ, 2014; (b) Kocienski, P. J. Protecting Groups; 3rd ed.; Thieme: Stuttgart, 2005.

(2) (a) Sieber, P. Helv. Chim. Acta 1977, 60, 2711; (b) Gerlach, H. Helv. Chim. Acta 1977, $60,3039$.

(3) Wood, J. L.; Thompson, B. D.; Yusuff, N.; Pflum, D. A.; Matthaeus, M. S. P. J. Am. Chem. Soc. 2001, 123, 2097.

(4) Serrano-Wu, M. H.; Regueiro-Ren, A.; St. Laurent, D. R.; Carroll, T. M.; Balasubramanian, B. N. Tetrahedron Lett. 2001, 42, 8593.

(5) (a) Allen, J. G.; Danishefsky, S. J. J. Am. Chem. Soc. 2001, 123, 351; (b) Forsch, R. A.; Rosowsky, A. J. Org. Chem. 1984, 49, 1305; (c) Fustero, S.; Garcia Sancho, A.; Acena, J. L.; Sanz-Cervera, J. F. J. Org. Chem. 2009, 74, 6398.

(6) (a) Vedejs, E.; Larsen, S. D. J. Am. Chem. Soc. 1984, 106, 3030; (b) Fustero, S.; Sanchez-Rosello, M.; Rodrigo, V.; Garcia, A.; Catalan, S.; del Pozo, C. J. Org. Chem. 2008, 73, 5617.

(7) Reeves, C. M.; Behenna, D. C.; Stoltz, B. M. Org. Lett. 2014, 16, 2314.

(8) (a) Bourne, G. T.; Horwell, D. C.; Pritchard, M. C. Tetrahedron 1991, 47, 4763; (b) Boger, D. L.; Yohannes, D. Tetrahedron Lett. 1989, 30, 5061; (c) Nicolaou, K. C.; Namoto, K.; Ritzen, A.; Ulven, T.; Shoji, M.; Li, J.; D'Amico, G.; Liotta, D.; French, C. T.; Wartmann, M.; Altmann, K.-H.; Giannakakou, P. J. Am. Chem. Soc. 2001, 123, 9313; (d) Baran, P. S.; Shenvi, R. A. J. Am. Chem. Soc. 2006, 128, 14028; (e) Horning, B. D.; MacMillan, D. W. C. J. Am. Chem. Soc. 2013, 135, 6442.

(9) (a) Narasaka, K.; Sakakura, T.; Uchimaru, T.; Guedin-Vuong, D. J. Am. Chem. Soc. 1984, 106, 2954; (b) Knutsen, L. J. S.; Judkins, B. D.; Newton, R. F.; Scopes, D. I. C.; Klinkert, G. J. Chem. Soc., Perkin Trans. 1 1985, 621; (c) White, J. D.; Amedio, J. C., Jr.; Gut, S.; Ohira, S.; Jayasinghe, L. R. J. Org. Chem. 1992, 57, 2270.

(10) (a) Jones, P.; Villeneuve, G. B.; Fei, C.; DeMarte, J.; Haggarty, A. J.; Nwe, K. T.; Martin, D. A.; Lebuis, A.-M.; Finkelstein, J. M.; Gour-Salin, B. J.; Chan, T. H.; Leyland-Jones, B. R. J. Med. Chem. 1998, 41, 3062; (b) Roush, W. R.; Madar, D. J.; Coffey, D. S. Can. J. Chem. 2001, 79, 1711; (c) Fürstner, A.; Bindl, M.; Jean, L. Angew. Chem., Int. Ed. 
2007, 46, 9275; (d) Reed, S. A.; White, M. C. J. Am. Chem. Soc. 2008, 130, 3316; (e) Cheng, Y.; Tang, S.; Guo, Y.; Ye, T. Org. Lett. 2018, 20, 6166.

(11) (a) Wallach, D. R.; Stege, P. C.; Shah, J. P.; Chisholm, J. D. J. Org. Chem. 2015, 80, 1993; (b) Wallach, D. R.; Chisholm, J. D. J. Org. Chem. 2016, 81, 8035.

(12) Duffy, B. C.; Howard, K. T.; Chisholm, J. D. Tetrahedron Lett. 2015, 56, 3301.

(13) Howard, K. T.; Duffy, B. C.; Linaburg, M. R.; Chisholm, J. D. Org. Biomol. Chem. 2016, 14, 1623.

(14) (a) Thierry, J.; Yue, C.; Potier, P. Tetrahedron Lett. 1998, 39, 1557; (b) Respondek, T.; Cueny, E.; Kodanko, J. J. Org. Lett. 2012, 14, 150.

(15) Shah, J. P.; Russo, C. M.; Howard, K. T.; Chisholm, J. D. Tetrahedron Lett. 2014, 55, 1740.

(16) Adhikari, A. A.; Shah, J. P.; Howard, K. T.; Russo, C. M.; Wallach, D. R.; Linaburg, M. R.; Chisholm, J. D. Synlett 2014, 283.

(17) Mahajani, N. S.; Meador, R. I. L.; Smith, T. J.; Canarelli, S. E.; Adhikari, A. A.; Shah, J. P.; Russo, C. M.; Wallach, D. R.; Howard, K. T.; Millimaci, A. M.; Chisholm, J. D. J. Org. Chem. 2019, 84, 7871.

(18) Ali, I. A. I.; El Ashry, E. S. H.; Schmidt, R. R. Eur. J. Org. Chem. 2003, 4121.

(19) Green, A. J.; Kuan, Y. L.; White, J. M. J. Chem. Soc., Chem. Commun. 1994, 2023.

(20) (a) Schmidt, R. R.; Effenberger, G. Liebigs Ann. Chem. 1987, 825; (b) Li, C.; Wang, J. J. Org. Chem. 2007, 72, 7431; (c) Devineau, A.; Pousse, G.; Taillier, C.; Blanchet, J.; Rouden, J.; Dalla, V. Adv. Synth. Catal. 2010, 352, 2881; (d) Wiebe, C.; Fuste de la Sotilla, S.; Opatz, T. Synthesis 2012, 44, 1385; (e) Adhikari, A. A.; Radal, L.; Chisholm, J. D. Synlett 2017, 28, 2335; (f) Suzuki, T.; Chisholm, J. D. Tetrahedron Lett. 2019, 60, 1325.

(21) Lambert, J. B.; Wang, G. T.; Finzel, R. B.; Teramura, D. H. J. Am. Chem. Soc. 1987, 109, 7838.

(22) Chiavarino, B.; Crestoni, M. E.; Lemaire, J.; Maitre, P.; Fornarini, S. J. Chem. Phys. 2013, 139, 071102/1. 